\title{
MAPA, MEMÓRIA, LOCALIDADE E ARQUIVO: DIÁLOGO LATINO-AMERICANO ${ }^{1}$
}

\author{
Haydée Ribeiro Coelho*
}

Resumo: Este texto focaliza o Diario, de Ángel Rama, publicado em 2001 (Uruguai). Para isso toma-se como ponto de partida a posição do autor Walter Mignolo (um dos representantes da crítica cultural contemporânea). Em seu livro Histórias locais/projetos globais: colonialidade, saberes subalternos e pensamento liminar trata da leitura de outros mapas afroculturais a partir de histórias locais. Tendo por base essa ideia, será mostrada que há a possibilidade de focalizar o Diário, de Ángel Rama, escrito em seu exílio na Venezuela, como um mapa intersticial que permite compreender a maneira como o escritor uruguaio estava realizando uma outra história da crítica literária latino-americana, pensada a partir do exílio, em um espaço sem fronteira.

\section{INTRODUÇÃO}

As questões teóricas, enunciadas no título, sobretudo aquelas relacionadas ao "mapa" e à "localidade", me foram suscitadas pela leitura de Walter Mignolo a partir de Histórias locais/projetos

\footnotetext{
${ }^{1}$ Este texto faz parte do projeto em curso, apoiado pelo CNPq. Ele constitui a primeira parte do texto apresentado na VIII Semana de Eventos da Faculdade de Letras, outubro 2008.

* Universidade Federal de Minas Gerais.
} 
globais: colonialidade, saberes subalternos e pensamento liminar. $\mathrm{Na}$ introdução do livro, o autor faz uma longa exposição, ressaltando que o pensamento liminar "busca compensar a diferença colonial que a tradução colonial (sempre unidirecional, como a globalização em nossos dias) tentava naturalizar como parte da ordem universal". ${ }^{2}$ Voltando-se para o sistema colonial moderno, escondido por sucessivas camadas e territórios mapeados, atenta para o mapa de Leslie Marmon Silko que mostra "em uma perspectiva transnacional, a história do sistema/colonial moderno do ponto de vista de uma história local específica". 3 Outros textos, como aqueles de Rigoberta Menchú e de Janet L. Abu-Lughod, constituem referência para a leitura de outros mapas sob o ponto de vista da colonialidade do poder.

Nesse contexto, é possível refletir sobre outros saberes, outros "loci" de enunciação e outros mapas críticos e literários, considerando a experiência do exílio, registrada no Diario, de Ángel Rama. Não é fortuito esse enfoque, tendo em vista o fato de o conceito da "transculturação", ${ }_{4}^{4}$ de Fernando Ortiz, retomado por Ángel Rama, ser restrito ao âmbito da nacionalidade, conforme Walter Mignolo. Nessa direção ainda, o Diario e todas as implicações que dele decorrem abrem um mapa intersticial que permite

\footnotetext{
${ }^{2}$ MIGNOLO. Histórias locais/projetos globais: colonialidade, saberes subalternos e pensamento liminar, p. 23.

${ }^{3}$ MIGNOLO. Histórias locais/projetos globais: colonialidade, saberes subalternos e pensamento liminar, p. 51.

${ }^{4}$ Walter Mignolo afirma: "O que falta na análise de Ortiz é a colonialidade, e falta porque, para Ortiz, a questão principal é a nacionalidade. Assim, a colonialidade situa a questão dentro mas também além da nação, no sentido em que os estados-nações estão firmemente estabelecidos no horizonte da colonialidade: ou o estado-nação torna-se um império (como a Espanha ou Inglaterra) ou, ao viver levantes ou rebeliões, torna-se autônomo enquanto caminha para a formação de uma nação (i.e. as Américas no fim do século $18 \mathrm{e}$ início do 19)." MIGNOLO. Histórias locais/projetos globais: colonialidade, saberes subalternos e pensamento liminar, p. 40.
} 
compreender como Ángel Rama no exílio estava traçando uma história da crítica literária latino-americana sobre as histórias já existentes.

O texto autobiográfico, do autor uruguaio, visto como encruzilhada de tempos e espaços, orienta o olhar do leitor para múltiplas direções. No entanto, neste texto, serão destacados os seguintes aspectos: o exílio, a viagem e o viajante; o crítico da cultura; o crítico literário e o Diario e, ainda, os hipertextos e outros textos.

Tendo confrontado o exílio de Darcy Ribeiro, registrado em Confissões e o de Ángel Rama com base no Diario, algumas questões, a serem apresentadas, tangenciam aspectos estudados no artigo "Darcy Ribeiro, Ángel Rama e exílio: rumo à identidade supranacional", 5 mas se enveredam por outras trilhas não percorridas.

O primeiro registro cronológico do diário ocorre em 1 de setembro de 1974, sendo interrompido entre os anos de 1975 e 1976. Rama retorna a escrever em 1977 (8 outubro), estendendo-se até 1983 ( 20 de abril de 1983 e 2 de maio). O diário tem especificidades que decorrem da modalidade discursiva, da condição do exílio e da atividade crítica e literária exercida por seu autor. Em relação ao primeiro aspecto, seria oportuno evocar a diferença entre autobiografia e diário, ressaltando que este oferece uma "realidade parcelar"; ' é uma "escrita do efémero"7 e "apresenta uma identidade pulverizada por descobrir e inventariar". ${ }^{8}$ Se "a autobiografia é uma retrospectiva, o diário, um devir". ${ }^{9}$ No "diário íntimo", segundo ainda Marcelo Duarte Mathias, "a introversão

${ }^{5}$ COELHO. Darcy Ribeiro, Ángel Rama e exílio: rumo à identidade supranacional, p. 169-192.

${ }^{6}$ MATHIAS. Autobiografias e diários, p. 46.

${ }^{7}$ MATHIAS. Autobiografias e diários, p. 46.

${ }^{8}$ MATHIAS. Autobiografias e diários, p. 46.

${ }^{9}$ MATHIAS. Autobiografias e diários, p. 46. 
constitui o elemento preponderante". ${ }^{10}$ A distinção entre as modalidades discursivas, tendo em vista o pacto autobiográfico, bastante estudada pelo crítico Wander Melo Miranda em Corpos escritos, tem, no meu texto, a função de situar o diário do autor do livro Transculturación narrativa en América Latina.

Por que Rama escreve o Diario?

Estava trabalhando em uma seleção dos diários íntimos do escritor venezuelano Rufino Blanco Fombona ${ }^{11}$ e, por associação, se recorda da leitura que ele fez dos Diarios de André Gide, na adolescência. As "feridas secretas" e os "temores" acompanham essa viagem singular do crítico exilado.

\section{O EXÍLIO, A VIAGEM E O VIAJANTE}

Nesse percurso compulsório, o viajante é tomado "por la sensación de inestabilidad"; ${ }^{12}$ se vê impossibilitado de criar raízes; em um "desconsierto vital". ${ }^{13}$ As expressões e as imagens presentes em "desfiladeros pedregosos"; "cataclismos"; "tierra que se resquebraja" e "peligros y acechanzas inevitables" 14 reforçam esse quadro reiterado em outras páginas do diário pela repetição do termo "insegurança" entrelaçado aos sentimentos de angústia e à ausência de perspectiva de futuro. As ideias de estranhamento, de ser estrangeiro nesse outro lugar (Venezuela, primeiro exílio), estão

\footnotetext{
${ }^{10}$ MATHIAS. Autobiografias e diários, p. 47.

${ }^{11}$ Rufino Blanco Fombona é uma das figuras decisivas da primeira metade do século XX (1874-1944) e grande parte de sua vida transcorreu na Europa, tendo como causa sua oposição frontal à ditadura de Juan Vicente Gómez, conforme demonstrei em texto já mencionado. (Cf. COELHO. Darcy Ribeiro, Ángel Rama e exílio: rumo à identidade supranacional, p. 179.)

${ }^{12}$ RAMA. Diario 1974-1983, p. 36.

${ }^{13}$ RAMA. Diario 1974-1983, p. 36.

${ }^{14}$ RAMA. Diario 1974-1983, p. 38.
} 
muito presentes nesse texto. O diário tem uma função de escuta: "no tengo con quien hablar". ${ }^{15}$ Em situação de errância, o autor se asila em seus escritos.

Uma cartografia dos exílios latino-americanos surge nas páginas do diarista (exílio cubano, chileno e o próprio exílio uruguaio), suscitando mapas justapostos que se conectam com outros. O mesmo tema aparece enfocado em ensaio de 1978, intitulado "La riesgosa navegación del escritor exiliado", publicado na revista Nueva Sociedad. Em edição póstuma, em 1998, o capítulo reaparece em livro do mesmo nome. Nessa direção, esclarece Horacio Machin:

"Literature and exile", es una versión modificada del artículo anterior que Rama publicó en la revista Nueva Sociedad (1978) y que le dió título a su libro póstumo $L a$ riesgosa navegación del escritor exiliado. Ambos artículos presentan una diferencia de formato que toma en cuenta el público al cual se dirijen: el venezolano está escrito como un ensayo latinoamericano, el norteamericano como um paper. Rama cierra su artículo de 1981 com una imagen del pueblo que guarda una homología con la del Angelus Nuevus en la novena de las "Tesis de filosofía de la historia" de Walter Benjamin (Benjamin, Illuminations).${ }^{16}$

Espelhos, representações, linguagens não se excluem, possibilitando perspectivas de quem vê o fora e o dentro. A voz do intelectual exilado é atravessada pela do crítico da cultura, da Literatura e aquela do Diretor Literário da "Biblioteca Ayacucho".

\footnotetext{
${ }^{15}$ RAMA. Diario 1974-1983, p. 87.

${ }^{16}$ MACHIN. Ángel Rama y "La lección intelectual de Marcha”, p. 86.
} 


\section{O CRÍTICO DA CULTURA}

A vinculação entre o intelectual e a cultura aparece sob outros ângulos, considerando os rumos da Revolução Cubana e do próprio exílio. A perspectiva política e militante de Ángel Rama, demonstrada em seus vários artigos escritos em Marcha em relação à cultura, à política cultural e à deterioração do regime democrático uruguaio, meados de 1966 até início de 1970, não abandona o crítico nas observações sobre a cultura venezuelana.

Em 1 de novembro de 1977, faz uma análise da relação entre a cultura, a editoração de livros e o processo democrático. Constata a falta de divulgação dos livros estrangeiros pela Editora Nacional Monte Ávila, tendo como consequência um aparato crítico ultrapassado. Esse aspecto de provincianismo seria decorrente dessa "anormal situación de enclausuramiento casi moral en que vivió el país bajo la larga dictadura de Gómez y que, curiosamente en vez de superarse resultó intensificado en el periodo de Pérez Jiménez (la década de los años cincuenta) como se percibe en los intelectuales". ${ }^{17}$

O olhar de Rama e a palavra fraturam o discurso acadêmico e o saber instituído. Em 9 de outubro de 1974, reportando-se a sua visita a Zulia (Venezuela), para proferir conferências sobre Rufino Blanco Fombona, aproveita para refletir sobre a riqueza do universo popular em contrapartida ao "universitario, mediocre intelectualizado puerilmente y el oligárquico refinado y ajeno a este torrente vivo". ${ }^{18}$ Essa citação encontra ressonância no texto de Walter Mignolo a propósito do saber e a genealogia segundo Michel Foucault:

Denominava genealogia a união de "saber erudito e memórias locais" e especificava que o que a genealogia faz é "apoiar o direito a atenção dos saberes locais,

\footnotetext{
${ }^{17}$ RAMA. Diario 1974-1983, p. 83.

${ }^{18}$ RAMA. Diario 1974-1983, p. 52.
} 
descontínuos, desqualificados, ilegítimos contra as pretensões de um corpo unitário de teoria que pretendia filtrar hierarquias e ordená-las em nome de um saber verdadeiro e uma idéia arbitrária do que constitui uma ciência e seus objetos. ${ }^{19}$

Sob esse aspecto, Rama reitera, no Diario, uma perspectiva teórica sobre a cultura, baseada em uma reflexão sobre a arte produzida pelas margens e, com certeza, vista a partir delas. Não é fortuito o fato de, no texto da Transculturación narrativa, Rama, na discussão da autoria indígena, com base no livro traduzido por Berta Ribeiro (Antes o mundo não existia) - realizado com histórias contadas e assinadas pelos próprios índios -, evidenciar como a incorporação dos textos indígenas ao sistema literário latinoamericano corresponde a uma transformação efetiva na concepção de literatura.

Quando o crítico uruguaio comenta a repercussão da "Biblioteca Ayacucho" no jornal venezuelano El Nacional, em 17 de setembro de 1974, questiona o monolinguismo e a colonialidade do poder espanhol que percebe os hispano-americanos como "retrasados colonos indignos de manejar un idioma que ellos no han creado y que no hacen sino deteriorar". ${ }^{20}$ Para elucidação desse aspecto, destaco, ainda, outro fragmento:

En El Nacional un periodista cultural (español, claro aunque avecindado en el país desde hace treinta anos) arremete contra nuestro proyecto de Biblioteca Ayacucho aduciendo los argumentos del Siglo XIX de Menéndez. Pelayo: que hay una unidad que presta la lengua y que por lo tanto sólo puede encararse una colección donde estén los c1ásicos,españoles. Hasta aquí es simplemente un extemporáneo uso de una

\footnotetext{
${ }^{19}$ MIGNOLO. Histórias locais/projetos globais: colonialidade, saberes subalternos e pensamento liminar, p. 45.

${ }^{20}$ RAMA. Diario 1974-1983, p. 39.
} 
tesis vieja que los españoles ya no aplican, ni de hecho nunca aplicaron: no existe ninguna biblioteca española (Ribadeneyra, Clásicos Castellanos) que incorpore a los hispanoamericanos en plano de igualdad con los castellanos y que junto a Bécquer publique a Sarmiento. ${ }^{21}$

No texto "Um processo autonômico: das literaturas nacionais a literatura latino-americana”, traduzido no Brasil em janeiro de 1974, Ángel Rama oferece um mapeamento fundamental para a compreensão dos vários momentos da escrita de uma história literária latino-americana. Depois de comentar a primeira Historia da poesia bispano-americana, escrita por Marcelino Menéndez Pelayo, atenta justamente para o caminho construído na busca de um percurso de superação dos modelos europeus. Nesse sentido, o Diario mantém um diálogo permanente com a obra teórica de Ángel Rama.

\section{O CRÍTICO LITERÁRIO}

Ángel Rama não adota uma posição ortodoxa em relação à crítica literária, fazendo uma distinção entre arte e militância política, como se pode observar nas anotações realizadas sobre 0 n. 85 (julho-agosto de 74), da Revista Casa de las Américas:

Acabo de ver el n.85 (julio-agosto 74) cuya sección de poesía (texto del premio del concurso y de los mencionados) es desoladora: editoriales seudo revolucionarios, pacotilla retórica, ni siquiera con las viejas obligaciones que imponía la rima y el ritmo hace cincuenta años a estos mismos productos. ${ }^{22}$

\footnotetext{
${ }^{21}$ RAMA. Diario 1974-1983, p. 38-39.

${ }^{22}$ RAMA. Diario 1974-1983, p. 45.
} 
Descontado o teor contundente da afirmação, reitera-se o que Saúl Sosnowvsky afirma a propósito de Ángel Rama: "se distanció de toda etiqueta redutora". ${ }^{23}$

O crítico uruguaio constrói breves retratos de autores que são estudados por ele como Julio Cortázar e Juan Rulfo. Vê-se que o diarista, ao captar o modo de olhar desses escritores, acaba observando a maneira como se apoderam das coisas, dos outros seres humanos, dos acontecimentos a partir de uma espécie de “duplo fantasmal”. É claro que esse registro de Rama não é uma simples anotação, mas uma forma de assinalar a mediação entre o modo de ver o mundo e sua construção que supomos ser literária, considerando os agentes envolvidos. O trecho destacado do Diario atenta para esse aspecto:

En Julio, como en Juan Rulfo, encuentro la misma respetuosa y considerada capacidad de atención para las cosas, los otros seres humanos, los sucesos o los objetos. Como si miraran fijamente todo eso, algo hipnotizados, pero a la vez distantes y circunspectos, como si se apoderaran de esas materias del mundo exterior a las que sin embargo no tocan, a las que dejan vivir indemnes en su medio y atmósfera, pero de las cuales se han aproiado de una suerte de doble fantasmal. ${ }^{24}$

Em seu Diario, Rama escreve sobre "sensibilidades", pontos de aproximação entre ele e Gabriel García Márquez. A motivação da escrita decorre da carta que o autor colombiano lhe envia pelo ensaio "La iniciación literaria de García Márquez.". O Diario possibilita uma outra escuta das cartas que não temos e do diário/confissão que podemos usufruir pela publicação. A origem popular e "esa impregnación de pueblo que hace su (mi)

\footnotetext{
${ }^{23}$ SOSNOWSKY. Ángel Rama: un sendero en el bosque de palabras, p. X.
}

${ }^{24}$ RAMA. Diario 1974-1983, p. 56. 
(nuestra) mayor sensibilidadad". ${ }^{25}$ São alguns desses pontos de aproximação entre o crítico uruguaio e o escritor colombiano.

\section{O DIRETOR LITERÁRIO DA “BIBLIOTECA AYACUCHO”}

Não é a primeira vez que faço referência à "Biblioteca Ayacucho". No entanto, volto a esse ponto tão importante pelo empreendimento que foi, pelos desdobramentos analíticos e pela metáfora anunciadora de outros caminhos como a crítica no pósexílio uruguaio. Citando, sucintamente, Rosario Peyrou, autora do prólogo e responsável pela edição e pelas notas do diário, ressalto que a "Biblioteca Ayacucho" constitui

um projeto ambicioso nascido com o motivo da comemoração do sesquicentenário de la Batalla de Ayacucho, que consagrou a independência da América. Os quinhentos volumes planejados recobrem as obras mais importantes da cultura latino-americana desde suas origens precolombianas, em diversos campos disciplinares: literatura, antropologia, filosofia, pensamento político. ${ }^{26}$

No Diario, Rama não se apresenta como "Diretor Literário" da "Biblioteca Ayacucho", mas a organização dessa grande obra em processo e outros aspectos a ela relacionados aparecem mencionados inúmeras vezes: o encontro com a delegação latinoamericana, incluindo os brasileiros para a discussão do projeto da Biblioteca; ${ }^{27}$ a repercussão da "biblioteca" no jornal El Nacional de Caracas; ${ }^{28}$ a expansão dos volumes publicados (vinte volumes,

\footnotetext{
${ }^{25}$ RAMA. Diario 1974-1983, p. 38.

${ }^{26}$ PEYROU. Prólogo, p. 20.

${ }^{27}$ RAMA. Diario 1974-1983, p. 36-37.

${ }^{28}$ RAMA. Diario 1974-198, p. 38-39.
} 
conforme registro de 9 de outubro de 1977) e o trabalho de elaboração do prólogo "El poeta frente a la modernidad" para o volume da "Ayacucho" dedicado a Rubén Dario).

\section{O DIARIO, OS HIPERTEXTOS E OUTROS TEXTOS}

O Diario oferece caminhos múltiplos, possibilitando ao leitor o acesso aos hipertextos decorrentes da itinerância do intelectual (Venezuela, Estados Unidos, Barcelona, Paris), do registro das várias atividades (crítico, professor, conferencista, diretor literário da Ayacucho e editor da revista Escritura); de encontros com artistas intelectuais e escritores latino-americanos de toda parte; da construção do retrato do crítico exilado; de fragmentos de retratos e comentários de obras. Aliado a esse aspecto tem-se outro. Se as notas feitas por Rosario Peyrou constituem um paratexto; os números referentes a elas no Diario remetem a outros hipertextos. Nesse quadro, instaura-se uma "complexa e não sequencial rede de associações."29

O leitor de Ángel Rama pode olhar para trás, isto é, em direção aos textos escritos em Marcha (jornal uruguaio) sobre a cultura; a política cultural para a América Latina e verificar que Rama polemizou, protestou contra a desintegração da sociedade liberal uruguaia que foi o "el espejo en el cual se contempló hermoseado". ${ }^{30}$

$\mathrm{Na}$ direção ainda de Marcha, o leitor encontra uma cartografia crítica sobre a literatura uruguaia e hispano-americana. Em relação ao primeiro aspecto, ressalte-se que o autor de o Diario buscava relacionar os textos uruguaios com outros sistemas literários e artísticos e atentava para formas da escritura inovadora no Uruguai e em autores uruguaios que estavam produzindo fora

\footnotetext{
${ }^{29}$ BERND. Literatura Comparada e literaturas periféricas. p. 41. Citado por Microsoft Corporation, 1993

${ }^{30}$ RAMA. Vida cultural 1967, p. 2.
} 
do país. É o que ocorre em relação ao escritor Luis Campodónico (1931-1973), autor de Estatua, conforme se observa no trecho:

Hacia mediados de la década del cincuentase promovió en América Latina una nueva vanguardia que renovó la concepción de la literatura, acometió una rigurosa experimentación, modernizó el instrumental literario, engendró nuevas lenguajes artísticos, incorporó escuelas y movimientos extranjeros. Ya ha pasado suficiente tiempo para medir los resultados de esta revolución que en la prosa narrativa nos ha deparado la obra de Mario Vargas Llosa y en la poesía la original creación del brasileño Haroldo de Campos jefe visible de la "poesía concreta". Por diversas razones locales, el Uruguay no se incorporó con decisión al movimiento y sólo unos pocos escritores (...), fueron capaces de encarar esta transmutación, la que habría de ser condenada a la indiferencia e al total desconocimiento masivo. Uno de ellos y de los más originales, fue Luis Campodonico que acaba de morir en París a los 42 años de edad. ${ }^{31}$

Em relação à literatura hispano-americana, foram vários os autores estudados e comentados por Rama no jornal Marcha. Citem-se: César Vallejo (peruano), Garcia Ponce (mexicano), Gabriel García Márquez (colombiano); Rodolfo Walsh (argentino); José Revueltas (México). Em novembro de 1968, o crítico uruguaio apresenta na íntegra o discurso de José María Arguedas por ocasião do recebimento do prêmio Inca Garcilaso de la Vega concedido ao escritor peruano.

O crítico acompanha toda movimentação político-cultural e literária na América Latina. Atento às inovações, publica "Sobre el techo de la Ballena" que se refere a um movimento de vanguarda na Venezuela nos anos 1960. Em Marcha, começava

${ }^{31}$ RAMA. Campodónico un adelantado, p. 31. 
mostrando o ambiente provinciano do Uruguai. Interpelando o leitor dizia que se esse não gostasse do assunto não prosseguisse:

Como escribo en un país donde la más cultivada flor del provincianismo, la que expresa su mediania y su mediocridad pequeño burguesa, es el sacro principio de la respeitabilidad, advierto al lector que tales flores han sido alegremente pisoteadas por el movimiento venezolano "El Techo de la Ballena". Si no le gusta no siga adelante. ${ }^{32}$

Em 1974, no ensaio "El techo de la Ballena", publica um longo texto sobre o mesmo movimento, mas a referência ao Uruguai desaparece. A visão que Rama tinha do provincianismo venezuelano, em decorrência do político, demonstra outras nuances pelo confronto entre textos. No contexto uruguaio, o provincianismo se referia ao campo literário. Esse é outro aspecto que possui inúmeros desdobramentos, por isso apenas registro os dois momentos de leitura a respeito do movimento de vanguarda na Venezuela nos anos 1960.

Pertenciam a esse movimento renovador os ficcionistas Adriano González León e Salvador Garmendía e os poetas Juan Calzadilla, Francisco Pérez Perdomo, Efraín Hurtado, Cauppollicán Ovalles, Dámaso Ogaz, Edmundo Aray e, ainda, os artistas plásticos Jacobo Borges e Carlos Contramaestre.

No ensaio de 1974, republicado em La riesgosa navegación del escritor exiliado, 1998, Rama mostra a importância e a diferença entre o movimento de vanguarda na Venezuela e os demais, atentando para:

Si fueron menos cultos que los escritores de la Mafia Mexicana (Carlos Fuentes, Juan García, Salvador Elizondo) o que los jefes de la poesía concreta de São Paulo (Haroldo y Augusto de Campos, Decio Pignatari)

${ }^{32}$ RAMA. Sobre el techo de la ballena, p. 30. 
y por consiguiente su esfuerzo de modernización se situó preferentemente en la adopción de las contribuciones ya consolidadas del surrealismo francés, con el agregado del descubrimiento de la poesía beatnik norteamericana (Ferlinghetti, Ginsberg), en cambio fueron capaces de un planteo político y social (a diferencia por ejemplo de los nadaístas que lo ignoran) y de un esfuerzo sistemático para integrar los distintos orbes de la vida humana - social, político, estético, vital - en un solo movimiento urgido. ${ }^{33}$

A "Biblioteca Ayacucho", vista não mais em processo, como aparece no Diario de Rama, mas como empresa já realizada, traz indagações sobre as questões teóricas anunciadas no início desse texto. Noé Jitrik, eminente crítico argentino, explica em entrevista que me foi concedida que os planejadores da "Biblioteca" buscavam, ainda, reafirmar a identidade latino-americana, decorrente de vários golpes militares. Segundo ele, "El exilio, además, de intelectuales de todos esos orígenes permitía escuchar voces nacionales en dimensión supranacional, lo cual ocorría basicamente en Venezuela y en México". ${ }^{34}$

Nessa direção, a "Biblioteca" representou um arquivo (no sentido de domicílio, de abrigo) ${ }^{35}$ da memória latino-americana sem que se fixasse em um estado-nação. Localidade desterritorializada, a "Biblioteca", saber sem fronteiras, trouxe para o mapa da América Hispânica o Brasil. Além da vertente político-cultural e literária, referente ao Brasil, a "Biblioteca" traçou também, em relação à América Hispânica, outros mapas político-culturais e literários.

A respeito dos mapas político-culturais, no I Congresso Internacional da Associação Brasileira de Hispanistas, realizado

\footnotetext{
${ }^{33}$ RAMA. Transculturación narrativa en América Latina, p. 82.

${ }^{34}$ JITRIK. In: COELHO. Las memorias de la memoria. El exilio de Darcy Ribeiro en Uruguay, p. 123.

${ }^{35}$ DERRIDA. Mal de arquivo: uma impressão freudiana, p. 12.
} 
na Faculdade de Letras da UFMG em 2008, lendo os prólogos de alguns dos livros editados pela Ayacucho, abriguei sob o título de "ethos emancipador - termo utilizado por Raphael Gutierrez Girardot, para se referir a Pedro Henriquez Ureña - os livros Doctrina del Libertador (Simón Bolivar); Ariel (José Enrique Rodó); Nuestra América (José Martí) e La nación latino-americana (Manuel Ugarte), e, sob a denominação de mapas antropológicos, literários e críticos, considerei Contrapunteo del tabaco y el Azúcar (Fernando Ortiz) e La crítica de la cultura en América Latina (Ángel Rama) e poderia citar outros, mas me ative a esses. Não significa, no entanto, que o primeiro mapa "ethos emancipador" não apresente conexão com o segundo, mas o ideário de independência e a luta contra o imperialismo estão presentes no primeiro.

Ángel Rama morreu em 1983, sem voltar ao Uruguai, mas o desenho de seu itinerário crítico ficou marcado no Diario, em seu corpo e naquele projetado na Coleção da "Ayacucho". Essas considerações, que resultam do estudo que realizei dos textos de Marcha, encontram pontos de contato com a entrevista de Noé Jitrik. Em relação à Biblioteca, afirma: "La idea era original de Rama, pero estaba respaldada por algunos intelectuales venezolanos que figuran en los primeros volumenes y que lo acompañaron con mucho entusiasmo." 36

Os mapas de Rama e suas inscrições na "Ayacucho de variadas formas semeiam um retorno, publicação e republicação de textos reunidos e selecionados por Saúl Sosnowski e Tomás Eloy Martínez no volume de n. 119, de La crítica de la cultura en América Latina. O primeiro autor evidencia como Rama soube acompanhar e interpretar as transformações do conhecimento que possibilitam formular "las memorias del futuro". ${ }^{37}$

\footnotetext{
${ }^{36}$ JITRIK. In: COELHO. Las memorias de la memoria. El exilio de Darcy Ribeiro en Uruguay, p. 120.

${ }^{37}$ SOSNOWSKY. Ángel Rama: un sendero en el bosque de palabras, p. XXIII.
} 
Tomando emprestada essa ideia de Saul Sosnovski, considero o Diario de Ángel Rama e a "Bibiblioteca Ayacucho" como mapas intersticiais que, em diálogo com o texto de Mignolo, criam passagens necessárias para se compreender as histórias locais, além do estado-nação e outros possíveis mapas teóricos transnacionais e, igualmente, latino-americanos.

Résumé: Ce texte analyse le Diario, d'Ángel Rama, publié en 2001 (Uruguay), en prenant comme point de départ la position de l'auteur Walter Mignolo, l'un des réprésentants de la critique culturelle contemporaine. Dans son livre Histórias locais/projetos globais: colonialidade, saberes subalternos e pensamento liminar, Mignolo traite de la lecture d'autres cartes géoculturelles à partir des histoires locales. Ayant pour base cette idée, nous allons montrer qu'il y a la possibilité de focaliser le Diario, de Ángel Rama, écrit dans son exil au Vénézuéla, comme une carte interstitielle qui permet de comprendre la façon dont l'écrivain uruguayen était en train de réaliser une autre histoire de la critique littéraire latino-américaine, pensée à partir de l'exil, dans un espace sans frontière.

\section{REFERÊNCIAS}

BERND, Z. Literatura comparada e literaturas periféricas. In: MARQUES, Reinaldo Marques; BITTENCOURT, G. N. (Org.). Limiares críticos. Belo Horizonte: Autêntica, 1998.

COELHO, H. R. (Org.). Las memorias de la memoria. El exilio de Darcy Ribeiro en Uruguay. Belo Horizonte: FALE/UFMG, 2003.

COELHO, H. R. Darcy Ribeiro, Ángel Rama e exílio: rumo à identidade supranacional. In: TOLENTINO, M. V. F. de (Org.). Nação e identidade: ensaios em literatura e crítica cultural. São João Del Rei: UFSJ, 2007.

DERRIDA, J. Mal de arquivo: uma impressão freudiana. Trad. Cláudia de Moraes Rego. Rio de Janeiro: Relume Dumará, 2001. 
JITRIK, N. In: COELHO, H. R. (Org.). Las memorias de la memoria. El exilio de Darcy Ribeiro en Uruguay. Belo Horizonte: FALE/UFMG, 2003.

MACHIN, H. Ángel Rama y "La lección intelectual de Marcha". In: MORÃNA, M. Ángel Rama y los estudios latinoamericanos. Pittsburg: Universidad de Pittsurg, 1997.

MATHIAS, M. D. Autobiografias e diários. Colóquio Letras, Lisboa, n. 143-144, p. 41-62, jan-jun. 1977.

MIGNOLO, W. D. Histórias locais/projetos globais: colonialidade, saberes subalternos e pensamento liminar. Trad. Solange Ribeiro de Oliveira. Belo Horizonte: Editora UFMG, 2003.

MIRANDA, W. M. Corpos Escritos. Graciliano Ramos e Silviano Santiago. São Paulo: EDUSP; Belo Horizonte: Editora UFMG, 1992.

PEYROU, R. Prólogo. In: RAMA, Ángel. Diario 1974-1983. Prólogo, edición y notas de Rosario Peyrou. Montevideo: Trilce, 2001. p. 5-30.

RAMA, Á. Nueva narrativa latinoamericana (II). Walsh en el tiempo del desprecio. Marcha, Montevideo, p. 28, 18 mar. 1966.

RAMA, Á. Diario 1974-1983. Prólogo, edición y notas de Rosario Peyrou. Montevideo: Trilce, 2001.

RAMA, Á. El techo de la ballena In: RAMA, Ángel. La riesgosa navegación del escritor exiliado. Montevideo: Arca, 1998.

RAMA, A. Introducción a Cien años de soledad. Marcha, Montevideo, 2 siet. 1967.

RAMA, A. José María Arguedas. No soy un aculturado. Marcha, Montevideo, p. 29, nov. 1968.

RAMA, Á. La riesgosa navegación del escritor exiliado. In: RAMA, Ángel. La riesgosa navegación del escritor exiliado. Montevideo: Arca, 1998.

RAMA, Á. Las prisiones de José Revueltas. Marcha, Montevideo, p. 29, 19 mayo 1972.

RAMA, Á. Luis Campodónico un adelantado Marcha, Montevideo, p. 31, 21 dic. 1973.

RAMA, Á. Nueva narrativa latinoamericana (I): El arte intimista de García Ponce. Marcha, Montevideo, p. 28, 11 mar. 1966. 
RAMA, Á. Sobre el techo de la ballena. Marcha, Montevideo, p. 30-31, 10 jun. 1966.

RAMA, Á. Transculturación narrativa en América Latina. Montevideo: Fondación Ángel Rama, 1998.

RAMA, Á. Un processo autonómico: das literaturas nacionais a literatura latino-americana. Trad. Nestor Deola. Argumento. Revista mensal de cultura, São Paulo, n. 3, p. 37-49.

RAMA, A. Vallejo viviente. Marcha, Montevideo, p. 31, 26 abr. 1968.

RAMA, A. Vida cultural 1967. Marcha, Montevideo, p. 2, 29 dic. 1967.

SOSNOWSKY, S. Ángel Rama: un sendero en el bosque de palabras. In: RAMA, Á. La crítica de la cultura en América Latina. Caracas: Biblioteca Ayacucho, 1985. p. IX-XXIII. 